\title{
On the hedging benefits of REITs: The role of risk aversion and market states
}

\author{
Riza Demirer $^{1} \bullet$ Asli Yuksel $^{2} \cdot$ Aydin Yuksel $^{3, *}$ \\ ${ }^{1}$ Department of Economics and Finance, Southern Illinois University Edwardsville, Edwardsville, USA \\ ${ }^{2}$ Department of International Finance, Bahcesehir University, Istanbul, Turkey \\ ${ }^{3}$ Department of Management, Isik University, Istanbul, Turkey
}

Received: 29 April 2020

Revised: 14 November 2020

Accepted: 13 January 2021

\begin{abstract}
We propose a dynamic, forward-looking hedging strategy to manage stock market risks via positions in REITs, conditional on the level of risk aversion. Our findings show that risk aversion can predict transitions to the high volatility regime in REIT markets when these markets are relatively calm. Accordingly, a hedge on/hedge off strategy based on the level of risk aversion with positions in REITs offer significant risk reduction for passive investors with the greatest benefits observed for the U.S. followed by the U.K. Our findings highlight the role of time-varying risk aversion as a predictor of REIT market volatility and the value of REIT investments as a hedge against stock market fluctuations.
\end{abstract}

Keywords: real estate investment trusts; risk aversion; Markov switching; hedging JEL Classification Codes: C22, C58, G14, G15

\section{Introduction}

Thanks to the advances in financial markets, the securitization of real estate in the form of real estate investment trusts (REITs) has allowed investors to take advantage of diversification and hedging benefits of these assets with lower transactions costs. In the academic literature, numerous papers have examined the inflation hedging benefits of real estate investments although empirical results provide mixed evidence in this regard. ${ }^{1}$ Despite the multitude of studies that focus on the inflation-real estate nexus, there is little evidence on whether or not real estate investments can help hedge stock market risk exposures. Clearly, from an investment perspective, the inflation hedging ability of REITs depends on the extent to which the real revenue they generate is preserved when price levels rise. However, this argument assumes away possible mispricing due to inflation illusions (e.g. Campbell and Vuolteenaho, 2004), which may lead to over (under) pricing of these assets during periods of low (high) inflation.

\footnotetext{
* Corresponding author. E-mail: aydin.yuksel@isikun.edu.tr.

Citation: Demirer, R., Yuksel, A., and Yuksel, A. (2021) On the hedging benefits of REITs: The role of risk aversion and market states, Economics and Business Letters, 10(2), 126-132.
}

DOI: $10.17811 /$ ebl.10.2.2021.126-132

${ }^{1}$ See Taderera and Akinsomi (2020) for a recent survey of the literature on inflation hedging with REITs. 
If, on the other hand, the inflation illusion effect is present in both stocks and REITs, then one can argue that aggregate stock market fluctuations can be hedged by taking offsetting positions in REITs. Against this background, this study proposes a novel, forward-looking hedging strategy wherein REITs are used to mitigate stock market risk exposures conditional on the level of risk aversion in the market. ${ }^{2}$

The proposed hedging strategy conditional on risk aversion is motivated by the evidence of a significant investor sentiment effect on REIT returns and volatility (e.g. Huerta-Sanchez and Escobari, 2018). To proxy sentiment, we build on the recent evidence in Demirer et al. (2019) that risk aversion captures predictive power over gold market volatility, which is also considered a traditional inflationary hedge, and utilize the time-varying risk-aversion measure developed by Bekaert et al. (2017). Examining monthly data over six largest national REIT markets, we show that aggregate market risk aversion indeed has predictive power over REIT market regime transitions across all countries in the sample. Based on this predictability, we devise a hedge on/hedge off strategy wherein a passive (unhedged) stock market investor assumes a hedge position in the local REIT index if high volatility is predicted and remains unhedged otherwise. Our findings show that REITs can offer significant hedging benefits for passive (unhedged) stock market investors in all markets, with the largest reduction in portfolio return volatility observed for the U.S. indicated by a reduction in return volatility as high as $25 \%$, followed by the U.K. Overall, our findings highlight the role of time-varying risk aversion as a predictor of regime transitions in REIT markets and the value of REIT investments as a hedge against stock market risks.

\section{Data and methodology}

We use monthly data for REIT and aggregate stock market indices for six countries (Australia, Canada, Italy, Japan, the U.K. and the U.S.) that represent more than $88 \%$ of the EPRA Global Real Estate Index (Ntuli and Akinsomi, 2017), obtained from Datastream. Excess stock market and REIT returns are computed using the one year government bond rate in each country as the risk-free rate. Risk aversion is proxied by the time-varying risk-aversion measure developed by Bekaert et al. (2017) based on a set of six financial instruments (term spread, credit spread, a detrended dividend yield, realized and risk-neutral equity return variance and realized corporate bond return variance). ${ }^{3}$ This measure is derived from a no arbitrage asset pricing model featuring time varying economic uncertainty and risk aversion based on a utility function in the hyperbolic absolute risk aversion (HARA) class. The model yields separate series to represent the time variation in economic uncertainty and risk aversion. While economic uncertainty is found to be correlated with credit spreads and measures of financial market volatility, risk aversion is substantially correlated with consumer confidence measures instead. The sample period runs from June 2002 through December 2016 based on the availability of the risk aversion data. Although not reported to save space, we observe that REIT returns are generally more volatile than those for the stock market index with Italy experiencing the greatest volatility in both markets. All return series are negatively skewed with fat tails, while the Jarque-Bera test rejects normality for all.

In order to account for the presence of high and low volatility states which is critical for the subsequent conditional hedging analysis, we first specify a Markov-switching model of REIT $\left(R_{i, t}\right)$ and stock market index returns $\left(R M_{i, t}\right)$ for country $i$ in month $t$ as

\footnotetext{
2 There is an extensive literature on the role of macroeconomic and valuation based indicators in portfolio selection. As Çakmaklı and van Dijk (2016) note, with a few exceptions, most macroeconomic variables do not seem to add any predictive power for stock returns beyond that provided by traditional valuation ratios and interest rate related variables (see also Christiansen et al., 2012 and Paye, 2012).

${ }^{3}$ Data on risk aversion is available on Nancy Xu's website at https://www.nancyxu.net/risk-aversion-index.
} 


$$
\left(R_{i, t}-R F_{i, t}\right)=\alpha_{i, S_{i, t}}+\beta_{i, S_{i, t}}\left(R M_{i, t}-R F_{i, t}\right)+\varepsilon_{i, t}
$$

where $R F_{i, t}$ is the risk-free rate for country $i$ in month $t, S_{i, t} \in\{1,2\}$ is the latent regime variable following a two-state, first order Markov process and the error term $\varepsilon_{i, t}$, with $\varepsilon_{i, t} \sim \operatorname{iid}\left(0, \sigma_{S_{i, t}}^{2}\right)$. This specification allows us to capture possible regime dependent market sensitivities for real estate stocks where regime changes in country $i$ are governed by time-varying transition probabilities defined as $p_{l m}^{i}=P\left(S_{i, t+1}=l \mid S_{i, t}=m\right)$ where $p_{l m}^{i}$ is the probability of being in regime $l$ at time $t+1$ given that the REIT market was in regime $m$ at time $t$ with $\sum_{l=1}^{2} p_{l m}^{i}=1$ $\forall l, m \in\{1,2\}$.

Building on the recent evidence that time-varying risk aversion contains predictive information over return volatility in financial markets (e.g. Demirer et al., 2019), we next examine the role of risk aversion as a predictor of regime transitions in REIT returns. For this purpose, we estimate a predictive model using the filtered Markov-switching probabilities associated with each country's low volatility state as the dependent variable and regress it against lagged risk aversion as

$$
\operatorname{asin} \sqrt{p_{i, t}}=\delta_{0}+\delta_{1} R A_{t-1}+e_{t}
$$

where asin is the arcsine function defined for values 0 to 1 and $R A_{t-1}$ is risk aversion for month $t-1 .{ }^{4}$ In this specification, focusing on the low volatility state allows us to explore how time varying risk aversion affects volatility in REIT markets when these markets are relatively calm. This allows for a practical approach given that financial markets will, on average, be in a calm state majority of the time which corresponds to the hedge-off periods when investors do not necessarily need to be hedged. Similar to Basher et al. (2018), we estimate Eq. 2 using a linear regression model and the t-statistics are based on the Newey-West correction. Note that transforming the probabilities allows us to use a linear regression model and the arcsine function offers a practical setting as it is defined for values from 0 to 1.

\section{Empirical findings}

Markov-switching model estimates presented in Table 1 indicate the presence of two distinct volatility regimes, implied by the significant chi-square estimates that support asymmetry between the two regimes in terms of regime-specific volatility. ${ }^{5}$ We observe significantly higher market betas for REIT returns during the high volatility regime for all countries except Italy, with the U.S. REITs displaying the highest sensitivity to market movements (1.923) in the high volatility regime.

Examining the results for the filtered probabilities extracted from the Markov-switching models, the findings reported in Table 2 provide strong evidence that time-varying risk aversion contains predictive information over regime transitions in all REIT markets in the sample. The negative and highly significant $\delta_{1}$ estimates in Table 2 imply that higher risk aversion in the previous month is associated with a lower probability of being in a low-volatility regime. Considering that risk aversion is, by construction, based on financial instruments including the term spread and credit spread, it is possible that high risk aversion reflects tightening funding conditions which in turn predicts volatility regimes in subsequent periods (Brunnermeier and Pedersen, 2009). Nevertheless, the findings provide strong evidence that time-varying risk aversion has predictive power over regime transitions in national REIT markets across the high and low volatility states.

\footnotetext{
${ }^{4}$ Basher et al. (2018) use a similar setting to examine the predictive power of oil price shocks on regime transitions in stock markets.

5 The regime classification measures (RCM) of Ang and Bekaert (2002) further confirm the accuracy of the estimated Markov-switching models. We observe the highest (lowest) RCM value of 49.12 (14.40) in the case of Canada (U.K.). A value close to 100 implies a model that poorly distinguishes between the two regimes.
} 
Table 1. Markov-switching estimates.

\begin{tabular}{lccc|ccc|cc}
\hline \hline & \multicolumn{3}{c}{ Low volatility state } & \multicolumn{3}{c}{ High volatility state } & \multicolumn{2}{c}{ Equality tests } \\
& $\alpha_{\mathrm{L}}$ & $\beta_{\mathrm{L}}$ & $\log (\sigma)$ & $\alpha_{\mathrm{H}}$ & $\beta_{\mathrm{H}}$ & $\log (\sigma)$ & $\beta_{\mathrm{L}}=\beta_{\mathrm{H}}$ & $\sigma_{\mathrm{L}}=\sigma_{\mathrm{H}}$ \\
\hline Australia & 0.002 & $0.508^{* * *}$ & $-3.708^{* * *}$ & $-0.022^{* *}$ & $1.123^{* * *}$ & $-2.878^{* * *}$ & 9.672 & 33.045 \\
& $(0.859)$ & $(6.866)$ & $(-53.869)$ & $(-2.106)$ & $(6.135)$ & $(-22.272)$ & $(0.002)$ & $(0.000)$ \\
Canada & $0.013^{* * *}$ & $0.171^{* *}$ & $-4.372^{* * *}$ & -0.005 & $0.782^{* * *}$ & $-3.287^{* * *}$ & 23.036 & 37.974 \\
& $(5.598)$ & $(2.310)$ & $(-25.166)$ & $(-1.171)$ & $(7.961)$ & $(-40.943)$ & $(0.000)$ & $(0.000)$ \\
Italy & 0.008 & $0.919^{* * * *}$ & $-2.953^{* * *}$ & -0.012 & $0.917^{* * * *}$ & $-2.145^{* * *}$ & 0.000 & 34.524 \\
& $(1.404)$ & $(7.677)$ & $(-32.941)$ & $(-0.583)$ & $(3.357)$ & $(-16.685)$ & $(0.995)$ & $(0.000)$ \\
Japan & $0.011^{* * *}$ & 0.048 & $-3.624^{* * * *}$ & 0.001 & $0.890^{* * *}$ & $-2.974^{* * *}$ & 36.926 & 26.629 \\
& $(3.003)$ & $(0.457)$ & $(-38.066)$ & $(0.207)$ & $(8.697)$ & $(-36.369)$ & $(0.000)$ & $(0.000)$ \\
UK & $0.007^{* *}$ & $0.884^{* * *}$ & $-3.432^{* * * *}$ & $-0.025^{*}$ & $0.993^{* * *}$ & $-2.571^{* * *}$ & 0.167 & 35.584 \\
& $(2.355)$ & $(10.393)$ & $(-48.573)$ & $(-1.731)$ & $(4.019)$ & $(-19.887)$ & $(0.683)$ & $(0.000)$ \\
US & 0.005 & $0.731^{* * *}$ & $-3.375^{* * *}$ & -0.020 & $1.923^{* * *}$ & $-2.732^{* * *}$ & 20.931 & 8.479 \\
& $(1.477)$ & $(7.738)$ & $(-44.019)$ & $(-1.183)$ & $(7.901)$ & $(-12.215)$ & $(0.000)$ & $(0.004)$ \\
\hline \hline
\end{tabular}

Note: The table reports the estimates for the Markov-switching model in Equation 1 (t-statistics based on robust standard errors reported in parentheses) $\log (\sigma)$ is the $\log$ of the regime-specific standard error estimate. ${ }^{* * *},{ }^{* *},{ }^{*}$ denote significance at $1 \%, 5 \%$ and $10 \%$, respectively. Equality tests report the computed chi-squared values and associated p-values (in parentheses) to test symmetry between the low and high volatility states. A p-value lower than 0.05 indicates rejection of the null of symmetry at the $5 \%$ level.

Table 2. The predictive power of risk aversion over filtered probabilities (low volatility state).

\begin{tabular}{lccr}
\hline \hline & $\delta_{0}$ & $\delta_{1}$ & \multicolumn{1}{c}{ Adj R ${ }^{2}$} \\
\hline Australia & $1.797^{* * *}$ & $-0.159^{* * * *}$ & $22.0 \%$ \\
\multirow{2}{*}{ Canada } & $(15.580)$ & $(-4.810)$ & \\
\multirow{2}{*}{ Italy } & $0.825^{* * *}$ & $-0.059^{* * *}$ & $3.6 \%$ \\
& $(6.955)$ & $(-2.107)$ & \\
Japan & $1.639^{* * *}$ & $-0.159^{* * *}$ & $27.2 \%$ \\
& $(17.976)$ & $(-8.279)$ & \\
UK & $1.049^{* * *}$ & $-0.098^{* * *}$ & $7.8 \%$ \\
& $(6.783)$ & $(-3.373)$ & \\
US & $1.762^{* * *}$ & $-0.161^{* * *}$ & $19.7 \%$ \\
& $(13.336)$ & $(-4.789)$ & \\
\hline \hline
\end{tabular}

Note: The table reports the estimated coefficients for the predictive value of risk aversion over filtered probabilities for the low volatility state as formulated in Equation 2 ( $\mathrm{t}$-statistics based on heteroskedasticity-consistent robust standard errors reported in parentheses). ${ }^{* * *},{ }^{* *},{ }^{*}$ denote significance at 1,5 and $10 \%$, respectively.

Given the predictive power of risk aversion over volatility and considering the literature on the hedging benefits of REITs (e.g. Lee, 2014), a significant investment implication is whether one can exploit the predictability patterns in a conditional hedge on/hedge off strategy wherein the investor conditions the decision to hedge or not on the state of REIT market volatility, as predicted by risk aversion. In this procedure, the REIT index is used as a hedging instrument to hedge stock market risks. For this, we consider a passive (unhedged) investor in a given country who is currently invested in the aggregate stock market index with the monthly return denoted as $R M_{t}$ (for simplicity, we drop the country subscript in the notation). As the hedge, the investor takes a short position in the local REIT index to form a hedge portfolio $(H P)$ with its return formulated as $R H P_{t}=R M_{t}-h_{t}^{*} R_{t}$ where $R M_{t}\left(R_{t}\right)$ is the return on the stock market (REIT) index in month t, respectively and $h_{t}^{*}$ is the hedge ratio. However, hedging is executed in a forward-looking manner, conditional on the REIT market volatility state such that the investor 
remains unhedged if low volatility is predicted for the next month and assumes the hedge position if high volatility is predicted.

For this purpose, we first define a month $t$ to be in high (low) risk aversion state if risk aversion for the month is greater (smaller) than the lagged 6-month risk aversion. ${ }^{6}$ Next, given the strong findings in Table 2 that high risk aversion predicts a lower probability of being in a lowvolatility regime, we construct a forward-looking hedging strategy wherein we assume a short position in the REIT index in month $(t+1)$ if month $t$ is identified to be in high risk aversion state and remain unhedged (i.e. invested in the market index only) in month $(t+1)$ if month $t$ is identified to be in low risk aversion state summarized as

$$
h_{t+1}^{*}=\left\{\begin{array}{l}
0(\text { i.e. unhedged }), \text { low risk aversion in month } t \\
\operatorname{cov}\left(R M_{t}, R_{i t}\right) / \sigma_{m t}, \text { high risk aversion in month } t
\end{array}\right.
$$

where the optimal hedge position $\left(h_{t+1}^{*}\right)$ for month $t$ is estimated as the minimum-variance hedge ratio with $\operatorname{cov}\left(R M_{t}, R_{i t}\right)$ and $\sigma_{m t}$ are the covariance between the market index and REIT returns and variance of market index returns, respectively, estimated using data over months $(t$, $t-24){ }^{7}$

Table 3. The performance of hedged portfolios against the passive (unhedged) market index.

\begin{tabular}{|c|c|c|c|c|c|c|c|c|}
\hline & & & \multicolumn{6}{|c|}{ Hedged Portfolios } \\
\hline & & & \multicolumn{3}{|c|}{$\begin{array}{l}\text { Panel A: } \\
\text { Estimation window }=24 \text { months }\end{array}$} & \multicolumn{3}{|c|}{$\begin{array}{c}\text { Panel B: } \\
\text { Estimation window }=36 \text { months }\end{array}$} \\
\hline \multirow{4}{*}{ Australia } & & Unhedged & $R A=6$ & $R A=12$ & $R A=18$ & $R A=6$ & $R A=12$ & $R A=18$ \\
\hline & Mean & $0.41 \%$ & $0.49 \%$ & $0.51 \%$ & $0.56 \%$ & $0.39 \%$ & $0.43 \%$ & $0.47 \%$ \\
\hline & Std. Dev. & $3.83 \%$ & $3.58 \%$ & $3.62 \%$ & $3.50 \%$ & $3.67 \%$ & $3.69 \%$ & $3.55 \%$ \\
\hline & $\mathrm{HE}$ & & $-6.54 \%$ & $-5.54 \%$ & $-8.70 \%$ & $-4.17 \%$ & $-3.57 \%$ & $-7.19 \%$ \\
\hline \multirow[t]{3}{*}{ Canada } & Mean & $0.51 \%$ & $0.56 \%$ & $0.46 \%$ & $0.56 \%$ & $0.51 \%$ & $0.37 \%$ & $0.50 \%$ \\
\hline & Std. Dev. & $3.84 \%$ & $3.51 \%$ & $3.36 \%$ & $3.26 \%$ & $3.57 \%$ & $3.42 \%$ & $3.28 \%$ \\
\hline & $\mathrm{HE}$ & & $-8.68 \%$ & $-12.47 \%$ & $-15.03 \%$ & $-6.94 \%$ & $-10.90 \%$ & $-14.51 \%$ \\
\hline \multirow[t]{3}{*}{ Italy } & Mean & $-0.01 \%$ & $-0.09 \%$ & $-0.05 \%$ & $0.02 \%$ & $-0.22 \%$ & $-0.24 \%$ & $-0.15 \%$ \\
\hline & Std. Dev. & $5.54 \%$ & $5.08 \%$ & $5.25 \%$ & $5.19 \%$ & $5.29 \%$ & $5.38 \%$ & $5.30 \%$ \\
\hline & $\mathrm{HE}$ & & $-8.39 \%$ & $-5.29 \%$ & $-6.36 \%$ & $-4.51 \%$ & $-2.89 \%$ & $-4.42 \%$ \\
\hline \multirow[t]{3}{*}{ Japan } & Mean & $0.28 \%$ & $0.23 \%$ & $0.27 \%$ & $0.42 \%$ & $0.27 \%$ & $0.30 \%$ & $0.48 \%$ \\
\hline & Std. Dev. & $5.11 \%$ & $4.62 \%$ & $4.69 \%$ & $4.63 \%$ & $4.77 \%$ & $4.83 \%$ & $4.75 \%$ \\
\hline & $\mathrm{HE}$ & & $-9.55 \%$ & $-8.29 \%$ & $-9.38 \%$ & $-6.60 \%$ & $-5.45 \%$ & $-7.07 \%$ \\
\hline \multirow[t]{3}{*}{ UK } & Mean & $0.33 \%$ & $0.24 \%$ & $0.32 \%$ & $0.41 \%$ & $0.19 \%$ & $0.27 \%$ & $0.36 \%$ \\
\hline & Std. Dev. & $4.23 \%$ & $3.64 \%$ & $3.61 \%$ & $3.63 \%$ & $3.76 \%$ & $3.72 \%$ & $3.73 \%$ \\
\hline & $\mathrm{HE}$ & & $-13.94 \%$ & $-14.70 \%$ & $-14.09 \%$ & $-11.07 \%$ & $-11.94 \%$ & $-11.88 \%$ \\
\hline \multirow[t]{3}{*}{ US } & Mean & $0.54 \%$ & $0.50 \%$ & $0.54 \%$ & $0.60 \%$ & $0.52 \%$ & $0.54 \%$ & $0.60 \%$ \\
\hline & Std. Dev. & $4.30 \%$ & $3.37 \%$ & $3.24 \%$ & $3.23 \%$ & $3.48 \%$ & $3.34 \%$ & $3.33 \%$ \\
\hline & $\mathrm{HE}$ & & $-21.62 \%$ & $-24.67 \%$ & $-24.88 \%$ & $-19.07 \%$ & $-22.23 \%$ & $-22.63 \%$ \\
\hline
\end{tabular}

Note: Unhedged (third column) refers to the passive strategy of investing in the stock market index $\left(R M_{i, t}\right)$ for country $i$. Active strategy refers to the hedge portfolio supplemented by short positions in the REIT index $\left(R H P_{i, t}=R M_{i, t}-h_{i, t}^{*} R_{i, t}\right.$ ), conditional on the risk aversion state in the prior month. Panels A (B) report the results based on $h^{*}$ values computed using a 24 (36) month estimation window, respectively. For robustness checks, in each panel, we use the average RA over the past 6-, 12-, and 18-months to determine the risk aversion state of the market. For each country, Mean and Std. Dev. are the mean and the standard deviation of monthly returns for the corresponding investment strategy. HE is the hedge effectiveness value computed as the percentage reduction in return volatility compared to the passive strategy.

\footnotetext{
${ }^{6}$ Similar results are obtained when the risk aversion state of a month is determined using lagged 12 and 18 month risk aversion (reported in Table 3).

${ }^{7}$ Similar results are obtained when the optimal hedge ratio is estimated using data over the past 36 months (reported in Table 3).
} 
Table 3 reports the return and hedging performance statistics for the passive against the actively hedged portfolios. For robustness check, we report in Panels A (B) the results based on $h^{*}$ values computed using a 24 (36) month estimation window, respectively. In order to ensure our findings are robust to how the risk aversion state is determined, in each panel, we use the average RA over the past 6-, 12-, and 18-months to determine the risk aversion state of the market. Hedging effectiveness (HE) values in the table clearly indicate that REITs offer significant hedging benefits in all countries, with the reduction in return volatility as high as $25 \%$ in the U.S., followed by the U.K. Clearly, REITs can offer significant hedging benefits to mitigate market risks for passive investors across all countries in the sample. This finding is consistent with Lee (2014) that stock market risk can be hedged by taking a short position in the REIT market. This finding is also in line with the evidence by Liow and Schindler (2014) of diversification ability of REITs at the country-level although our findings suggest that the state of risk aversion in the market can be used as a signalling condition. In short, our findings suggest that REITs have the potential to offer risk reduction benefits for passive equity investors and time varying risk aversion can be utilized in a hedge on/hedge off style strategy in a forward looking manner. Finally, although not reported due to space consideration, examining the descriptive statistics for the estimated hedge ratios for each country, we observe that hedge ratios are well below unity, suggesting that relatively smaller positions in REITs would be required to hedge stock market risk, leading to lower cost of hedging in the proposed strategy.

\section{Concluding remarks}

In this paper, we provide novel insight to the hedging benefits of real estate investments for equity investors using a sample of six countries that represent more than $88 \%$ of the EPRA Global Real Estate Index. Establishing strong evidence of predictability patterns with respect to time-varying risk aversion, we propose a dynamic, forward-looking hedging strategy in which a hedge position in the REIT index is taken conditional on the REIT market volatility state, predicted by the level of risk aversion during the prior month. Compared to the passive (unhedged) portfolio represented by the aggregate stock market index, an active hedging strategy that utilizes positions in REITs conditional on the level of risk aversion yields significant risk reduction. We observe that the benefit of hedging can be as high as $25 \%$ (U.S.) which is a significant reduction in return volatility compared to the passive stock market index. The findings suggest that the predictive power of time-varying risk aversion over volatility regimes can be utilized in active hedging strategies that involve REITs with the potential to reduce significant variability in passive portfolio returns.

\section{Acknowledgements}

We would like to thank an anonymous referee for many helpful comments; any remaining errors are solely ours.

\section{References}

Ang, A., and Bekaert G. (2002) Regime switches in interest rates, Journal of Business and Economic Statistics, 20, 163-182.

Basher, S. A., Haug, A. A., and Sadorsky, P. (2018) The impact of oil-market shocks on stock returns in major oil-exporting countries, Journal of International Money and Finance, 86, 264-280.

Bekaert, G., Engstrom, E. C., and Xu, N. R. (2017) The time variation in risk appetite and uncertainty, working paper.

Brunnermeier, M., and Pedersen, L. (2009) Market liquidity and funding liquidity, The Review of Financial Studies, 22, 2201-2238. 
Campbell, J. Y., and Vuolteenaho, T. (2004) Inflation illusion and stock prices, American Economic Review Papers and Proceedings, 94, 19-23.

Çakmaklı, C., and van Dijk, D. (2016) Getting the most out of macroeconomic information for predicting excess stock returns, International Journal of Forecasting, 32, 650-668.

Christiansen, C., Schmeling, M., and Schrimpf, A. (2012) A comprehensive look at financial volatility prediction by economic variables, Journal of Applied Econometrics, 27, 956-977.

Demirer, R., Gkillas, K., Gupta, R., and Pierdzioch, C. (2019) Time-varying risk aversion and realized gold volatility, North American Journal of Economics and Finance, 50 (November), 101048.

Huerta-Sanchez, D., and Escobari, D. (2018) Changes in sentiment on REIT industry excess returns and volatility, Financial Markets and Portfolio Management, 32, 239-274.

Lee, Y. H. (2014). An international analysis of REITs and stock portfolio management based on dynamic conditional correlation models, Financial Markets and Portfolio Management, 28, 165-180.

Liow, K. H., and Schindler F. (2014) An asssessment of the relationship between public real estate and stock markets at the local, regional and global levels, International Real Estate Review, 17(2), 157-202.

Ntuli, M., and Akinsomi, O. (2017) An overview of the initial performance of the South African REIT Market, Journal of Real Estate Literature, 25(2), 365-388.

Paye, B. S. (2012) 'Déjà vol': Predictive regressions for aggregate stock market volatility using macroeconomic variables, Journal of Financial Economics, 106, 527-546.

Taderera, M., and Akinsomi, O. (2020) Is commercial real estate a good hedge against inflation? Evidence from South Africa, Research in International Business and Finance, 51, 101096. 